\title{
"Good Bye Casa", una Cura Creativa en lima, Perú para el DESMANTELAMIENTO DE LA CIUDAD
}

Orietta Marquina Vega ${ }^{1}$

Pontificia Universidad Católica del Perú, Lima, Perú

\begin{abstract}
Después de aplicar un programa económico neoliberal y encarcelar a Abimael Guzmán, jefe del grupo terrorista Sendero Luminoso, el paisaje de Lima habia cambiado. Muchas de las personas más solventes económicamente habian huido del pais por la guerra interna que asoló al Perú. Sus casas, ahora, debian dar paso a nuevos habitantes en Lima. El crecimiento económico trajo nuevos capitales extranjeros interesados en invertir; pero, también, nuevas formas de vivir y habitar la ciudad. Unas artistas mujeres organizaron intervenciones artisticas en estas casas próximas a ser demolidas como resistencia a las nuevas relaciones sociales que las nuevas edificaciones proponian a la ciudad y sus nuevos habitantes. No habia espacio para chicos jugando al fútbol en las calles, ni chicas y chicos coqueteando en las esquinas. Los artistas jóvenes decidieron presenciar desde sus ruinas, al menos durante algunos dias, el mundo del que se vieron obligados a despedirse.
\end{abstract}

Palabras clave: afectos, transformaciones urbanas, abandono urbano, intervenciones artísticas, ruinas urbanas

\section{INTRODUCCIÓN ${ }^{2}$}

En el Perú, como en muchos países latinoamericanos, usamos la palabra "casa" para nombrar, no solo el edificio donde vivimos, sino también nuestro lugar y hogar. Significa un territorio con el cual nos sentimos relacionados, al cual pertenecemos, donde nos sentimos seguros y pro-

1 Contacto de la autora: orietta.marquina@pucp.edu.pe

2 Una versión en inglés de este artículo se presentó como ponencia en la Conferencia 2018 de ASA (Association of Social Anthropologists of the UK and Commonwealth): Sociality, Matter, and the Imagination: Re-creating Anthropology, llevada a cabo del 18 al 21 de setiembre del 2018 en los Examination Schools, University of Oxford, UK. 
bablemente nos permitamos actuar libremente. La casa es el lugar que habitamos. Entendemos "el habitar como una conexión material y corporal con la arquitectura y la evocación del lugar" (Relph 1976; Tuan 1977; Buttimer y Seamon 1980; Heidegger 1988; Seamon 1993; Mugerauer 1994; Ingold 2000 citados por Kraftl y Adey 2008: 214). La casa funciona como un espacio personal cuya materialidad revela nuestra propia coexistencia social dotada de significado (Maíz 2001). Es personal y social simultáneamente.

Su materialidad encarna nuestra historia y el conjunto de relaciones intersubjetivas que establecemos con ella y con los demás seres en nuestro entorno. La casa es tanto un ambiente físico como un espacio afectivo. "Mi casa es tu casa", solemos decirle a la gente que sentimos y pensamos cercana a nosotros. Así la invitamos a ingresar a nuestra esfera, no solo privada sino también afectiva y emotiva. La casa, como espacio intersubjetivo, afectivo y emocional es, junto con el ritual de la comida, punto de partida para el inicio o fortalecimiento de nuevas relaciones interpersonales. Conocer a alguien e invitarlo a nuestra casa para cenar es mostrarle, no solo nuestra hospitalidad, sino también nuestro deseo de construir un vínculo de intimidad que lo enlace con nuestra cotidianeidad. La casa es un lugar que afecta a sus habitantes y que, simultáneamente, se ve afectada por ellos.

Los lugares son historias fragmentarias y remotas, un pasado robado a la legibilidad por el vecino, acumulando tiempos que pueden desarrollarse, pero que se parecen más a historias en espera que permanecen en estado de jeroglíficos, en resumen, simbolizaciones arraigadas en el dolor o el placer del cuerpo ${ }^{4}$ (De Certeau 1996: 121).

El barrio era una extensión de la casa y los vecinos que lo habitaban, una extensión de nuestra propia familia. Era el espacio social originario por excelencia en Lima. Ahí, encontrábamos a nuestros primeros amores y construíamos amistades cercanas. Ahí, nosotras, las niñas, aprendíamos a seducir, mientras, los niños eran liberados al libre albedrío del arte del fútbol y el humo de sus primeros cigarrillos. Ahí, empezábamos a conocernos a nosotros mismos y a los otros distintos a nosotros. Aprendíamos a reconocernos y a reconocerles como seres humanos, como hombres o mujeres, como peruanos. Ahora, el barrio, como tal, casi se ha ido. ¿Qué sucede cuando la "casa" comienza a desmoronarse?

Entre los años 1980 y 2000, el Perú experimenta el conflicto armado interno más intenso, extenso y prolongado de su historia republicana (CVR., 2003). El Partido Comunista del Perú, Sendero Luminoso (PCP-SL) ${ }^{5}$, es el movimiento terrorista que inicia el conflicto en mayo de 1980 y tuvo a Abimael Guzmán, apodado entre sus miembros como Presidente Gonzalo, como su principal líder y perpetrador de crímenes durante el conflicto armado. El saldo fatal que deja este conflicto armado es de casi 70000 víctimas fatales (Macher 2012). La mayoría de ellas fueron habitantes de las zonas rurales más olvidadas del Perú. Este conflicto tuvo sus inicios en Ayacucho, una de las regiones más pobres de la sierra central sur, y reveló profundas y dolorosas divisiones y malentendidos al interior de la sociedad peruana. Si bien el sector rural fue, desde sus comienzos, el centro de operaciones de Sendero Luminoso (SL), Lima y otras ciudades fue-

3 Traducción propia, el texto original dice: "inhabitation as a material, bodily connection with architecture and the evocation of place".

4 Traducción propia, el texto original dice: Places are fragmentary and withdrawn histories, past stolen to the legibility by the neighbour, piled up times that can unfold, but that are there more like stories waiting and that remain in state of hieroglyph, in short, symbolizations entrenched in the pain or pleasure of the body .

5 Si bien el nombre oficial de esta organización fue este. Coloquialmente se le denomina solo Sendero Luminoso (SL). De aquí en adelante, en este documento, se le denomina así. 
ron empleadas como cajas de resonancia para demostrar su poder. Los sectores urbanos fueron escenarios del asesinato de dirigentes populares, autoridades civiles y altos jefes militares (CVR, 2003). La mayoría de las ciudades, pero Lima en especial, vio su cotidianeidad afectada por sabotajes, asesinatos selectivos, actos terroristas y hasta paros armados que la dejaban constantemente sin luz y generaban un sentimiento de enorme inseguridad personal y ciudadana (CVR, 2003). Surgen rejas y vigilantes por toda la ciudad que cierran muchas de las calles limeñas haciendo que, para ir de un lugar a otro, la línea recta deje de ser la distancia más corta. La gente en los parques se torna sospechosa. Los espacios públicos se quedan sin públicos.

En 1992, el asesinato de María Elena Moyano, dirigente popular del distrito autogestionario de Villa El Salvador y el atentado de Tarata, una callecita en pleno corazón de Miraflores, uno de los distritos turísticos y de clase media más tradicionales de la ciudad, marcan un hito que hiere profundamente a Lima. Veinticinco muertos y más de ciento cincuenta heridos fue el resultado de la explosión de dos coche-bombas con cuatrocientos kilos de dinamita combinada con anfo (CVR, 2003). Por primera vez, los alcaldes de dos distritos completamente diferentes, uno con recursos, Miraflores, y otro sin ellos, Villa El Salvador, encabezaron una marcha por la paz en un intento de mostrar que la sociedad civil asumía el combate a Sendero Luminoso (SL). Meses después en ese mismo año, Abimael Guzmán es capturado por las fuerzas del orden. SL sufre un fuerte revés, pero continúa actuando fuera de Lima.

Es dentro de este contexto de terror, inseguridad, angustia y desesperanza que a comienzos de los años 1990, con el gobierno de Alberto Fujimori, se inicia la aplicación de un programa económico neoliberal que cambia dramáticamente la cara de Lima (Ludeña 2010). Al miedo y la desconfianza que ya el terrorismo había impregnado en la sociedad limeña se agrega un nuevo modelo urbanístico de ciudad fragmentada ${ }^{6}$ (Bärb y Borsdorf, 2012) en el que los limeños ya no pasean en los parques sino en el mall de su barrio haciendo que el espacio público brille por su ausencia o se privatice. Entre los años 2007 y 2012, se produjo un boom inmobiliario en Lima $^{7}$. Muchas casas fueron demolidas y muchos edificios fueron construidos en su reemplazo. Alrededor del año 2005, jóvenes artistas comenzaron a realizar intervenciones artísticas en estas casas próximas a ser demolidas. SL; Fujimori, con el neoliberalismo, y el modelo de ciudad fragmentada, con el boom inmobiliario, transforman al Perú en una suerte de país en ruinas que contagia esa sensación y sentimiento a Lima y a la vida social del grupo de artistas jóvenes que, sin ser totalmente conscientes de ello, se refugian en este accionar artístico para encontrar la cercanía y cobijo mutuo que les permita sobrellevar este proceso de transformación de su habitar.

Este trabajo busca explorar cómo el deshabitar y el habitar, la demolición y la construcción están relacionadas por los encuentros afectivos que esos proyectos artísticos posibilitaban. Nos enfocamos en uno de ellos: Good Bye Casa. Este fue un proyecto multidisciplinario desarrollado en Lima, entre los años 2008 y 2012. Su sitio blog.8 señala que "el objetivo (...) es entrar

\footnotetext{
6 Según Bärb y Borsdorf (2012) una ciudad fragmentada es aquella donde predominan barrios cerrados dentro y fuera de su perímetro; donde los que los servicios y elementos socio-espaciales se definen libremente dentro de espacios pequeños, como dichos barrios, y ya no a nivel de las grandes ciudades. Se trata de una nueva organización social de las ciudades en donde los habitantes de altos y bajos ingresos no están separados por barreras claramente definidas por sus ingresos, sino por sus estilos de vida y donde el espacio urbano está cada vez más privatizado.

7 En ese período, los precios en términos reales de los departamentos de Lima Metropolitana aumentaron en un 66\%. Mientras que, en los cinco distritos más ricos, dicho aumento fue del 100\% (Cuba 2013).

8 Dirección del Blog http://goodbyecasa.blogspot.com/
} 
e intervenir en los espacios de una casa, que será demolida, utilizarlo como soporte creativo y que éste sea un lugar de exposición". Good Bye Casa fue creado y desarrollado por el Colectivo Extramuros ${ }^{9}$, un grupo de tres artistas: Jennifer Castro-Morante, escultora, Alicia Huamalí, escultora, y Mercedes Espinoza, poeta. La información que presentamos aquí se recolectó de sus blogs y páginas del Facebook. Información complementaria se obtuvo de una entrevista en profundidad a una de las artistas del colectivo, y a otro del graffiti. Finalmente, también se incluye nuestras propias experiencias de participación como artista visual en algunas de estas acciones artísticas.

Este artículo se desarrolla en tres partes. Primero, explicamos cómo el afecto revela la vida cotidiana en un modo relacional y da a las personas un sentido de existencia para vivir en las ciudades. Segundo, describimos los encuentros afectivos que surgieron de Good Bye Casa, el proyecto artístico. Tercero, identificamos qué formas sociales e imaginarios emergieron de las intervenciones artísticas relacionadas con el desmantelar y el habitar la ciudad a través del afecto; ayudando a los artistas a superar el sentimiento de abandono que estas transformaciones urbanas les producían.

\section{EL AFECTO COMO FORMA DE REVELAR LA VIDA COTIDIANA}

Concordamos con Ingold (2013) que es a través del hacer que la vida cotidiana se concretiza en la realidad. Son nuestras rutinas de acción, personas, objetos y lugares conocidos los que dan estabilidad y continuidad a nuestra vida. Es su ocurrencia y presencia o su disrupción y ausencia lo que nos ayuda a diferenciar lo cotidiano de lo extraordinario. Así, las urbes son construcciones sociales siempre en progreso, que se desarrollan a partir del pasado, que sus habitantes pudieron construir, y los ideales de futuro, que deciden compartir.

Las ciudades son lugares fragmentarios, que funcionan unitariamente a través de las relaciones sociales, económicas, políticas, tecnológicas, culturales y emocionales que sus habitantes construyen en ciertos territorios a lo largo de su vida cotidiana. "En las vidas de la gente común, el archivo personal de recuerdos, tanto materiales como cognitivos, no está referido sola y principalmente al pasado, sino también a proveer un mapa para negociar y dar forma a nuevos futuros (Appadurai 2015: 378)". Precisamente, su carácter de construcciones sociales las hace "el área deseable y más eficaz para la gestión del desarrollo. (...) Cambia con el tiempo, al igual que los grupos humanos que lo ocupan, transformándose permanentemente y afectando el medio ambiente $^{10}$ (Ballón, Campana y Glave 2015: 155)”. Es en este proceso de construcción social de la ciudad que sus habitantes establecemos vínculos materiales. Definimos pensamientos, sentimientos y actitudes que nos permiten establecer fronteras y límites a la realidad para comprenderla en breve. Y, precisamente, son los afectos los que cambian la amplitud o frecuencia con que estos eventos influyen en nosotros o en los otros.

\footnotetext{
9 Dirección del Facebook https://www.facebook.com/pages/category/Artist/ColectivoExtramuros-138208079580926/

10 Traducción propia, el texto original dice: "the desirable and most effective area for the management of development. (...) It changes over time, just as human groups who occupy it do, transforming themselves permanently and affecting the environment."
} 
En el caso de Lima, el proceso de desmantelar la ciudad había comenzado ya con la acción de SL. Muchas personas habían fugado fuera del país en busca de mejores horizontes de futuro. Con Fujimori, Lima atraviesa una serie de transformaciones físicas y funcionales que cambian las relaciones entre sus propios habitantes y entre ellos y el lugar de la ciudad donde viven, con la promesa de que aquella metamorfosis los haría entrar al mundo desarrollado que la globalización hace ver de manera cercana. Lo que los limeños y limeñas no sabíamos es que dicho proceso de globalización impone la sustitución de lugares por flujos y espacios de información que homogenizan hábitos y costumbres, provocando un proceso de alienación como seres humanos que nos aísla, desarticula y desviste de nuestros referentes culturales, históricos y naturales. Es, entonces, que el afecto emerge como la forma en que cada situación modula el ser-allí para dar sentido a nuestra existencia.

"El afecto se refiere a un dominio emotivo [...] pero su alcance va mucho más allá de la subjetividad o el yo ${ }^{11}$ (Navaro-Yashin 2009: 12)". En él, nosotros “integramos emociones como conocimiento con reflexión crítica ${ }^{12}$ (Boler y Zembylas 2016: 19)”. El afecto reconceptualiza nuestro mundo interno. Hace que deje de ser un lugar de origen, auténtico o pre-cultural cuya universalidad y naturaleza contrasta con un mundo exterior cultural y civilizado. "Los afectos no son sobre ti o sobre él, sean sujeto u objeto. Son relaciones que inspiran al mundo ${ }^{13}$ (Dewsbury et al 2002: 439, énfasis agregado, citados por Kraftl y Adey 2008: 215)”. Nuestro mundo exterior se transforma en un objeto de la imaginación y del deseo (Lutz 2017). Esta reconceptualización del mundo exterior de las personas cambia, también, la forma en que entendemos la vida social y coloca a la vida afectiva y emocional como el centro de la misma.

$\mathrm{El}$ afecto revela la vida cotidiana "en sintonía con las formas y fuerzas que se desarrollan en las escenas y encuentros ${ }^{14}$ (Stewart 2017: 192)”con los demás. Redefine lo real y su materialidad, así como la manera en que estos se construyen y cambian. Lo hace a través de las diferentes relaciones que, de manera equívoca y no unívoca, establecemos entre lo social y lo personal, lo público y lo privado. El afecto nos exige una nueva forma de ver el mundo que emerge de los encuentros entre los cuerpos que ocurren a lo largo del tiempo y la ciudad (Kraftl y Adey 2008). Se convierte en un espacio relacional donde la intersubjetividad juega definiendo un aquí y ahora específico.

Sin embargo, el desarrollo del espacio urbano limeño subordina el punto de vista de la convivencia al económico. Aquí, la priorización del espacio para la circulación vehicular sobre aquel para la circulación peatonal es un claro ejemplo de dicha perspectiva. Así, la vida de los habitantes de las ciudades se desarrolla en medio de dos presiones: la dinámica del desarrollo económico y la de la falta de espacios públicos para la convivencia. Sin embargo,

Un mundo cargado de afecto es una zona de contacto prolífica y de uso mixto en un estado continuo de transición que deja a las personas "improvisando con lo que ya-se-siente" (Manning 2009, 30). El sujeto emerge en los arriesgados trabajos de estar en el mundo, a través de las precisas formas que las fuerzas toman en la

11 Traducción propia, el texto original dice: "Affect does refer to an emotive domain, broadly speaking, but its scope goes much beyond that of subjectivity or the self."

12 Traducción propia, el texto original dice: "integrate emotions as knowledge with critical reflexión."

13 Traducción propia, el texto original dice: "affects are not about you or it, subject or object. They are relations that inspire the world."

14 Traducción propia, el texto original dice: "attuned to the forms and forces unfolding in scenes and encounters." 
vida misma ${ }^{15}$ (Stewart 2017: 194).

El afecto se refiere a la configuración en común construida por nuestras experiencias vividas. Son modulaciones que, a manera de actos repetidos y eventos en todas las dimensiones de nuestra vida, funcionan como un segundo campo de acción de lo social a través de recuerdos y experiencias. Su pragmática nos da consistencia y permite dar sentido al aquí y ahora. La vida cotidiana hace sentido una vez más.

\section{"GOOD BYE CASA", UN PROYECTO ARTÍSTICO}

Jennifer, Alicia y yo estudiamos juntas en la Escuela Nacional Superior Autónoma de Bellas Artes del Perú (ENSABAP). Conocí a Mercedes en la primera intervención de una casa. Ellas son hijas del conflicto interno y el consecuente desmantelamiento de la ciudad. Estaban en sus veintipocos años de edad, cuando formaron el Colectivo Extramuros, cuyo blog ${ }^{16}$, dice:

Extramuros, más allá de las paredes del cubo blanco. Busca crear una conexión con la ciudad, con la gente. Por tanto, apunta por la interacción siendo esencial el diálogo, la reacción, que nace a partir de la observación de los diferentes proyectos que se efectúan. Tomado del poema Urbanismo (léase el poema) de Martín Adán. (Colectivo Extramuros, julio 2008)

Esta presentación marca desde un inicio su rechazo a la realidad aséptica que la modernidad proponía, libre del caos y la contradicción que el afecto y la emoción introducen. Así, "el afecto se convierte en una fuerza de indeterminación social que nos ofrece la oportunidad de ver lo que [algo] es, imaginar lo que [ese algo] podría ser en su lugar, y comprender que este "en su lugar de" está ya siempre sucediendo" (Bakko y Merz 2015: 8). Además, con "más allá del cubo blanco" remarcan la necesidad de la interacción y el diálogo como formas de encuentro con los otros, que el afecto propicia para cuestionar y anular las barreras del entendimiento mutuo, permitiéndonos ser por un momento. Cuerpo y discurso, afecto y razón, es lo que proponen como configuradores de lo real. Además, "Urbanismo", del poeta peruano Martín Adán, es una burla de lo que la civilización industrial ha traído al entorno en que vivimos intercambiando el verde del pasto por el gris del cemento. Así, este Colectivo se posiciona desde su ser interior para encontrarle sentido a lo que hacen y concretar, así, un compromiso de acción con la ciudad. El mismo blog agrega que

El Colectivo Extramuros, enlaza las artes plásticas con la utilización de la palabra [...] objetos, materiales diversos de la cotidianidad para descontextualizarlos y darle así una nueva percepción. El objetivo está en generar desde cuestionamientos internos hasta el sublime deseo de sentirnos comprometidos con la obra misma. Siempre con la participación activa del espectador hacia la acción que se realiza. [...] Las acciones realizadas por Extramuros empiezan a mediados de abril del 2008, por la necesidad de expresarse en forma colectiva en un mundo lleno de individualidades. Es preciso indagar desde nuestras fuentes internas, para que desde allí sobre nuestra realidad bombardeada por lenguajes disímiles, procedamos a construir la acción que se ejecutará en un espacio y tiempo definido por la urbe. (Blog Colectivo Extramuros, julio 2008)

Este interés por la ciudad no debe sorprender. Si bien, las ciudades se convierten en espacios de aglomeración para la generación del valor financiero a partir de la producción económica de servicios especializados, la Lima que ellas frecuentaban era otra. La ENSABAP, la antigua

15 Traducción propia, el texto original dice: "A world charged with affect is a prolific, mixed-use contact zone in an ongoing state of transition that leaves people "improvising with already-felts" (Manning 2009, 30). The subject emerges in the risky labours of being in a world through the precise forms that forces take in lives".

16 Ir a: https://colectivoextramuros.blogspot.com/ 
y primigenia escuela nacional de bellas artes, donde la mayoría de ellas y yo estudiábamos, se encuentra ubicada en una de las zonas más antiguas del centro histórico de Lima: los Barrios Altos. Esta área está llena de edificios antiguos del siglo XVI y la mayoría de sus habitantes son pobres o muy pobres. El paisaje urbano que rodea a la ENSABAP muestra, principalmente, un abandono y pobreza; que al mismo tiempo, contrasta con muchas micro y pequeñas empresas, el antiguo mercado de abastos de la ciudad, la más antigua estación de bomberos, el Barrio Chino y el Parlamento Nacional: Todos localizados en esa misma área. Los Barrios Altos son un barrio muy tradicional, pero lleno de todas las contradicciones que conviven en la ciudad. Su paisaje geográfico, en las horas en que los negocios e instituciones no funcionan, habla de decadencia y desolación aunque durante el día está lleno de personas de diferentes procedencias que van de un lugar a otro. Su materialidad abandonada contrasta con las vigorosas relaciones humanas que tienen lugar allí. Bien dice Stewart (2017: 194) que "la vida tiene lugar en los gestos inhumanos de los demonios y los ángeles, en las luchas de los adictos y la ira de los racistas, en la resistencia de los increíblemente heridos o los extrañamente curiosos ${ }^{17}$.

E1 Colectivo Extramuros comenzó sus acciones artísticas utilizando flores con el proyecto "La Rebelión de las Flores". Ellas solían recoger flores de la basura en el mercado de flores o comprarlas a las vendedoras al final del día, antes que las tiraran a la basura. Luego, las artistas caminaban por los Barrios Altos y otras calles del centro histórico de Lima en busca de muros a medio derruir y aceras, puertas, ventanas, etc. en estado de abandono y deterioro físico. A continuación, colocaban una o varias flores en esas materialidades heridas para curar el daño que mostraban. Es curioso que tanto ellas como las flores y la ciudad son todas femeninas. Ese sello femenino será una característica que las diferencia de las acciones que otros colectivos implementaban.

Otra acción artística, que el Colectivo Extramuros solía realizar y repetir en muchos barrios de Lima, fue el proyecto "Más Manos Más" con globos en forma de mano. Lima es una ciudad con pocas áreas verdes y menos flores en los jardines. Jennifer, Alicia y Meche solían hacer talleres de pintura en un parque o plaza pública e invitaban a pintar al menos un globo con forma de mano, a vecinos y personas que transitaban por la zona y las calles aledañas. Estos globos en forma de mano, luego de ser pintados, eran colocados sobre la hierba de los jardines pretendiendo funcionar como las flores que no tenían ${ }^{18}$.

Estas acciones artísticas del Colectivo Extramuros en el espacio público no fueron aisladas. Stewart (2010) propone que los afectos son modulaciones que toman la forma de actos repetidos de cuidado y potencialidad, a través de los cuales el ser humano se siente seguro o bienvenido. En esos momentos, había una gran cantidad de artistas que impulsaban el arte callejero en Lima. Con el programa económico neoliberal aplicado en el país a partir de 1990, muchas industrias se declararon en quiebra y la mayoría de los sindicatos perdieron su poder. En ese contexto el graffiti, que solían hacer estos sindicatos y militantes de partidos de izquierda para propagandizar sus luchas gremiales y políticas, había entrado vigorosamente en el mundo del arte de Lima. Aunque, existían algunos artistas haciéndolo ya desde antes, el siglo XXI encontró a Lima con muchos artistas grafiteros, la mayoría de ellos hombres, que pintaban edificios abandonados o cualquier pared que se pudiera pintar sin ir a la cárcel. Fueron hombres y muje-

17 Traducción propia, el texto original dice: "Life takes place in the inhuman gestures of demons and angels, in the struggles of addicts and the rage of racists, in the endurance of the unbelievably injured or the oddly still curious."

18 Ir a: https:/www.facebook.com/Colectivo-Extramuros-138208079580926/ 
res jóvenes, de 16 a 30 años de edad, los que realizaron estas acciones artísticas. Eran los hijos e hijas del terrorismo vivido durante su primera infancia. Eran jóvenes que encontraron en los procesos creativos, que desarrollaban a través del graffiti, un proceso liberador y reconciliador con ellos mismos que les proporcionaba una nueva identidad provisional, basada en lo heterogéneo, canalizando la acción individual hacia el afecto y no hacia la agresión.

Cuando el boom inmobiliario comenzó a correr más rápido, varios artistas del graffiti comenzaron a usar casas a ser demolidas para celebrar reuniones y fiestas. Lo hacían para recaudar dinero para la compra de insumos para realizar sus graffitis. En dichas fiestas, los artistas organizadores cobraban poco dinero por la música pero permitían desarrollar graffitis en sus muros. Al día siguiente, la casa era demolida. Sin embargo, aunque sea por una noche, dicha casa a medio derruir daba cobijo a estos jóvenes artistas y fungía de útero materno que les permitía ser. Sus creaciones permitían a cada uno expresarse libremente, explorando y explorándose a su manera.

Es en este contexto que el Colectivo Extramuros decidió realizar el proyecto artístico denominado Good Bye Casa. En su blog dice:

Caminando entre paisajes urbanos, nuestras miradas son golpeadas por construcciones tras destrucciones que vienen siendo realizadas en espacios-seres que perdieron su valor para la sociedad ahora son tratadas como simple materia a punto de ser desaparecidas, representando así metáforas de nuestras situaciones sociales. Sus condiciones de casas vacías abandonadas reflejan cuán importante fueron ellas para sus habitantes, los cuáles se encontraron seducidos por el mejor postor, el cual creará nuevas edificaciones necesarias para el desarrollo de la modernidad. Más allá de etiquetar si son buenas o malas éstas realidades...se trata de comprender lo que está aconteciendo en nuestra ciudad: la mutabilidad del espacio dentro del paisaje urbano donde convergen lo natural, lo histórico, los lazos fraternales amicales, lo ideológico, lo social, etc. (Blog Good Bye Casa, setiembre 2008)

La idea de "espacio-seres" habla de lugar, de un territorio apropiado que va más allá del espacio cartesiano. Dicha descripción es la de un territorio afectado que, además, afecta a sus habitantes. Y es que "la experiencia colectiva del espacio -como la del tiempo- responde a las posibilidades de construcción simbólica intersubjetiva de ese ámbito de conexiones reales donde se proyecta la coexistencia social dotada de sentido" (Vidal, 1999 en Maíz, 2001, segundo párrafo). El espacio, como realidad autodeterminada ontológicamente por el sujeto que la percibe, se ve imbuida del afecto que, como resultado de la experiencia interpersonal, actúa como una fuerza "que sacude a la subjetividad, moviéndola a la acción" (Aubán 2017: 75). Así, el blog de Good Bye Casa continúa diciendo

Busquemos transmitir estas experiencias interviniendo y apropiándonos de estas casas, que van a ser demolidas, a través de actos físicos (transgresión, roturas, incisiones al espacio), con proyecciones mentales que vinculen diversas zonas de la casa o también usando los residuos dejados como testimonio de días mejores. (Blog Good Bye Casa, setiembre 2008)

En todo momento, la convocatoria nos habla de intervenciones y apropiaciones que demandan la acción de nuestro cuerpo para colocar a la emoción y el afecto en el mismo plano de la razón y el pensamiento (Aubán 2017).

El Colectivo Extramuros comenzó a hablar con propietarios, arquitectos, ingenieros y supervisores de edificios para tener acceso gratuito a las casas, listas para ser demolidas, no solo por una noche, sino por un día o dos. Esta tarea no fue fácil. Un día la gente decía que sí, pero al día siguiente decía que no. Tampoco había fechas límite. Las empresas de construcción no 
trabajan con un horario exacto. La planificación de la acción artística no era posible. La mayoría de las veces, el Colectivo Extramuros sabía que tenían una casa disponible con solo unas pocas horas de anticipación. Para difundir las noticias entre la red de artistas usaban correos electrónicos, mensajes y llamadas telefónicas. Cualquier persona interesada podía participar. No había horarios específicos, más allá del lapso de disponibilidad que tenían para el usufructo de la casa en proceso de demolición. La casa estaba disponible día y noche durante la intervención artística. Los interesados en participar solo tenían que llevar consigo sus ideas, entusiasmo, habilidades y materiales. No había ningún cobro en absoluto. Antes de devolver la casa, las artistas invitaban a los vecinos de los alrededores a entrar a mirar las obras de arte y despedirse de la casa . Sin embargo, esta parte de la intervención artística no siempre funcionaba bien.

Los vecinos las miraban con desconfianza. ¿Quiénes son esos locos que se divierten tanto en esa casa deshabitada? ¿Son ladrones? ¿Son terroristas? ¿Qué están haciendo adentro? ¿Para qué lo hacen si la casa será demolida de inmediato? ¿Qué quieren de nosotros? ¿Es seguro entrar a la casa con ellos? Funcionó solo una vez. La gente entró a la casa y le contó al Colectivo Extramuros sobre la antigua familia que vivía allí: quiénes eran, qué les sucedió y dónde estaban en ese momento. Al final de la primera intervención artística, escribí:

Todas trabajábamos...cada una en lo suyo. Risas, bromas, abrazos, se mezclaban con silencios laboriosos, con aportes solidarios a los problemas que cada proyecto nos planteaba. Era una atmósfera cálida, íntima... muy femenina. De repente caí en la cuenta de que las convocantes eran todas mujeres., pero no sólo ellas, sino que la casa también era una "ella"...Pensé en la anterior invitación de Vale ${ }^{19}$. Allí los convocantes fueron mayoritariamente hombres...La intervención de esa casa también se llevó a cabo en un ambiente festivo y relajado...lleno de energía positiva. La convocatoria fue hecha con mayor anticipación, [...] fue casi masiva. Los interventores, también mayoritariamente hombres, utilizaron preferentemente el graffiti en sus diferentes variantes $[\ldots]$ Claro, pensé, en esa acción, predominó lo masculino...lo público.

No me había percatado de esa diferencia antes...No, no quiero caer en el cliché de que los hombres son de Marte y las mujeres somos de Venus. Na' que ver. Pero me pareció interesante como constatación. ¿Sería por eso que me fue más fácil participar activamente? ¿Cómo estaría sintiéndose ella? La casa, dominio ancestral de las mujeres, tradicional bastión de su identidad, de sus dominios...la familia. ¿Pasaría esto por la mente de las chicas y los chicos? ¿Sería relevante esto para ellos? No lo sé...No creo...

Sus propuestas me hablaban de una Venus marciana y de un Marte venusiano. Las propuestas de Ali, Jenny y Meche no eran tímidas ni débiles. Eran arriesgadas física y emocionalmente. En el caso [...] de Vale, los proyectos, si bien mostraban un ducho manejo de escena, estaban teñidos de humor y ternura (Marquina 2008).

A medida que pasaba el tiempo, a pesar de todos los esfuerzos del Colectivo Extramuros, cada vez era más difícil acceder a las casas. Las empresas inmobiliarias se estaban volviendo más sofisticadas y la entrada de grandes empresas al trabajo de demolición lo tiñe de la impersonalidad característica del neoliberalismo y capitalismo actual. Cada vez era más difícil solicitar el acceso a las casas y los tiempos, demasiado cortos para las convocatorias a los artistas. Dentro del circuito de arte también se producen cambios y se entra a la lógica de las ferias de arte. Adicionalmente, los artistas estaban perdiendo la motivación para participar en estas intervenciones artísticas. Finalmente, el Colectivo Extramuros se separó en el año 2012.

19 Vale, es una forma abreviada del nombre del artista visual Valentino Sibadón quien era miembro del Colectivo El Codo. Para ver su trabajo ir a: http://valentinosibadon.com/blog/ 


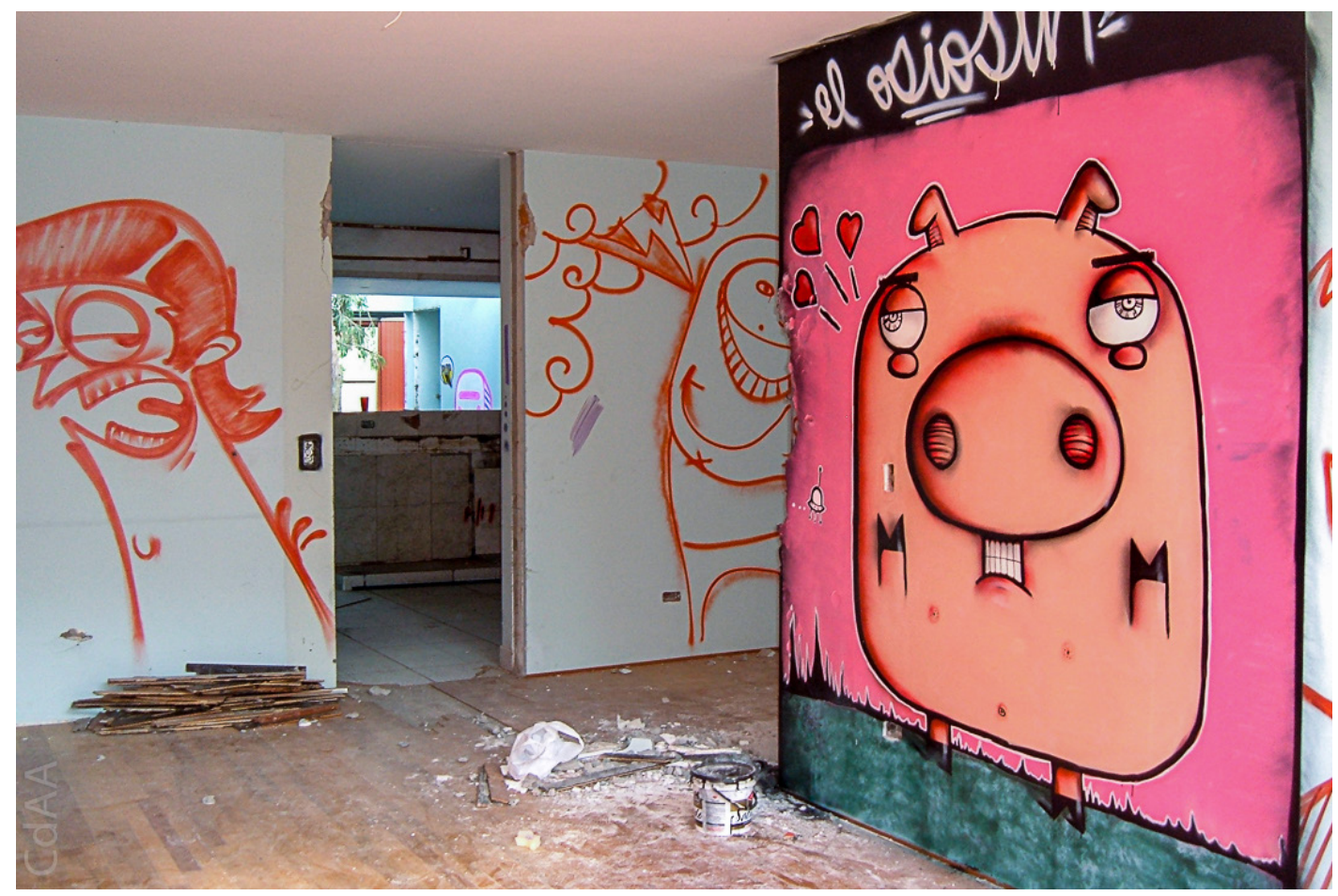

Foto 1. Fotografía por Orietta Marquina Vega.

\section{SANAR CREATIVAMENTE EL ABANDONO Y EL HABITAR}

A diferencia de otras ciudades latinoamericanas, la globalización en Lima no significó un nuevo punto de partida. Desde su independencia política, el "Perú es un país estructuralmente fragmentado, de mercado permanentemente desregulado, de ciudades duales, con un imaginario colectivo sin referentes estables" (Ludeña 2010: 6). Incluso hoy, ad portas de celebrar el bicentenario de nuestra independencia, el Perú carece de un liderazgo colectivo que lo ayude a construir un futuro en común.

Al mirar retrospectivamente, la experiencia de Good Bye Casa y el accionar del Colectivo Extramuros, pienso en la vinculación que existe entre el pasado y el futuro. En esos momentos, la difusión de los llamados "vladivideos" ${ }^{\text {"2o }}$ mostró toda la corrupción del gobierno de Fujimori, contribuyendo a que existiera un sentimiento mayoritario de que el país se encontraba en ruinas. Se vivía en un completo abandono y el habitar era difícil de lograr. Solo se sobrevivía.

Y era frente a ello que los jóvenes se resistían. "Ruina es tanto el reclamo sobre el estado de una cosa como el proceso que lo afecta"21 (Stoler 2008:195). La ruina tampoco tiene que ser material. Podemos pensar en una ruina como un aquí y ahora que no ofrece la futuros alternativos posibles. El presente es algo tan efímero que no bien termina de configurarse como tal, ya se convierte en pasado. El futuro, en cambio, es un hecho cultural que exige, a los habitantes de

20 Los vladivideos eran grabaciones de video caseras que mostraban a Vladimiro Montesinos, entonces asesor presidencial, sobornando a diferentes personajes políticos, empresariales y del ambiente artístico. El primer vladivideo se transmitió por televisión de cable el 14 de setiembre del 2000 y precipitó la renuncia de Fujimori.

21 Traducción propia, el texto original dice: "'Ruin” is both the claim about the state of a thing and a process affecting it”. 
la ciudad, imaginación, anticipación y aspiraciones (Appadurai 2015). Sin ellas la vida diaria no tendría ningún sentido.

Los jóvenes artistas resistieron afectando y dejándose afectar por otros a través de los encuentros afectivos que Good Bye Casa les ofreció. Apelaron al poder cultural de sus acciones artísticas para forjarse una visión de futuro más humana que aquella que los cambios en la ciudad ofrecía. Los artistas se organizaron y al responder al llamado del Colectivo Extramuros demostraron ser capaces de sentir e imaginar mundos alternativos a partir de un interés propio. Frente al abrumador tamaño de las transformaciones urbanas, ser capaces de crear les mostró a los participantes que había una puerta abierta en otro lugar gracias a su imaginación (ver foto 1). Además, contra la velocidad de las transformaciones urbanas, ser capaz de realizar sus proyectos de arte reflejaba una capacidad de hacer, una agencia que les permitía congelar, aunque sea temporalmente, un aquí y ahora que le daba existencia a sus vidas, permitiéndoles crear aspiraciones (ver foto 2). Es más, los jóvenes artistas, anticipando su posible derrota en términos individuales frente al avasallador desmantelamiento de la ciudad, participaron en las intervenciones artísticas con formas colectivas de actuar que los hicieron sentirse empoderados. La sensación de seguridad y protección los invadía les permitía improvisar y, finalmente, poder pensar que un futuro era posible.

Los encuentros afectivos del proyecto artístico Good Bye Casa ayudaron a los artistas a temporalmente superar los cambios urbanos de Lima. Hay, todavía, mucho más trabajo por hacer. Los liderazgos individuales e individualistas de los últimos gobernantes no miraron al Perú con afecto ni como su lugar de pertenencia. De los últimos siete presidentes que gobernaron el país desde $1990^{22}$, con la honrosa excepción de Valentín Paniagua, que dirigió el proceso de transición luego de la renuncia al cargo, vía fax, de Fujimori, dos están presos (Fujimori y Toledo), dos están siendo investigados por el caso Odebrecht ${ }^{23}$ (Humala y Kuczynski), uno se suicidó para no ser acusado por el mismo cargo (García) y el último, Martín Vizcarra, está todavía en funciones.

Desde nuestro punto de vista, el poder cultural es el llamado a contrarrestar la lógica del poder económico y la falta de amor que la transformación urbana de Lima refleja. Lo cultural desde el espacio público brinda una experiencia de identidad, pertenencia e historia que contribuye a construir el aquí y ahora necesario para que el cambio emerja.

Nuestra relación con la ciudad siempre ha sido cercana y emotiva. Yo tuve la suerte de nacer en una Lima alegre y salerosa, muy versátil como espacio urbano. Tiene un carácter cos-

22 Dichos presidentes son Alberto Fujimori (1990 -2000), Valentín Paniagua (2000 - 2001), Alejandro Toledo (2001 - 2006), Alan García (2006 - 2011), Ollanta Humala (2011 - 2016), Pedro Pablo Kuczynski (2016 - 2018$)$ y Martín Vizcarra (2018 - 2021).

23 "Odebrecht es la principal constructora de Brasil y América Latina, con 168.000 empleados y presencia en 28 países, como Perú, Colombia y Estados Unidos. [...] A partir de la operación Lava Jato, el juez Sérgio Moro, responsable de la investigación, señaló que Odebrecht formó un "club" para conseguir las licitaciones y un sistema "sofisticado" de lavado de dinero, con cuentas en Brasil y el extranjero. [...] Odebrecht está en el Perú desde 1979, durante el gobierno militar de Francisco Morales Bermúdez, y constituyó no menos de 27 empresas. Ha participado, individualmente o consorciada, en proyectos de infraestructura. Odebrecht se presentaba a licitaciones tanto con empresas que llevaban su nombre como con firmas de distinto nombre. En el 2016 se destaparon los casos de corrupción.[...] Ante la justicia estadounidense, Marcelo Odebrecht reconoció el pago de US\$29 millones en sobornos a funcionarios de gobierno peruano entre los años 2005 y 2014, que involucra a los ex presidentes Alejandro Toledo, Alan García y Ollanta Humala. En ese lapso, Odebrecht obtuvo US\$143 millones en beneficios ilegales”. Fuente: "Caso Lava Jato". En: Proética, capitulo peruano [on Line] Recuperado de https://www.proetica.org.pe/ casos-emblematicos/caso-lava-jato/ 
mopolita, pero mantiene un calor humano que desafortunadamente está desapareciendo poco a poco. Nos resistimos a aceptarlo, sin ofrecer nuestra mejor pelea.

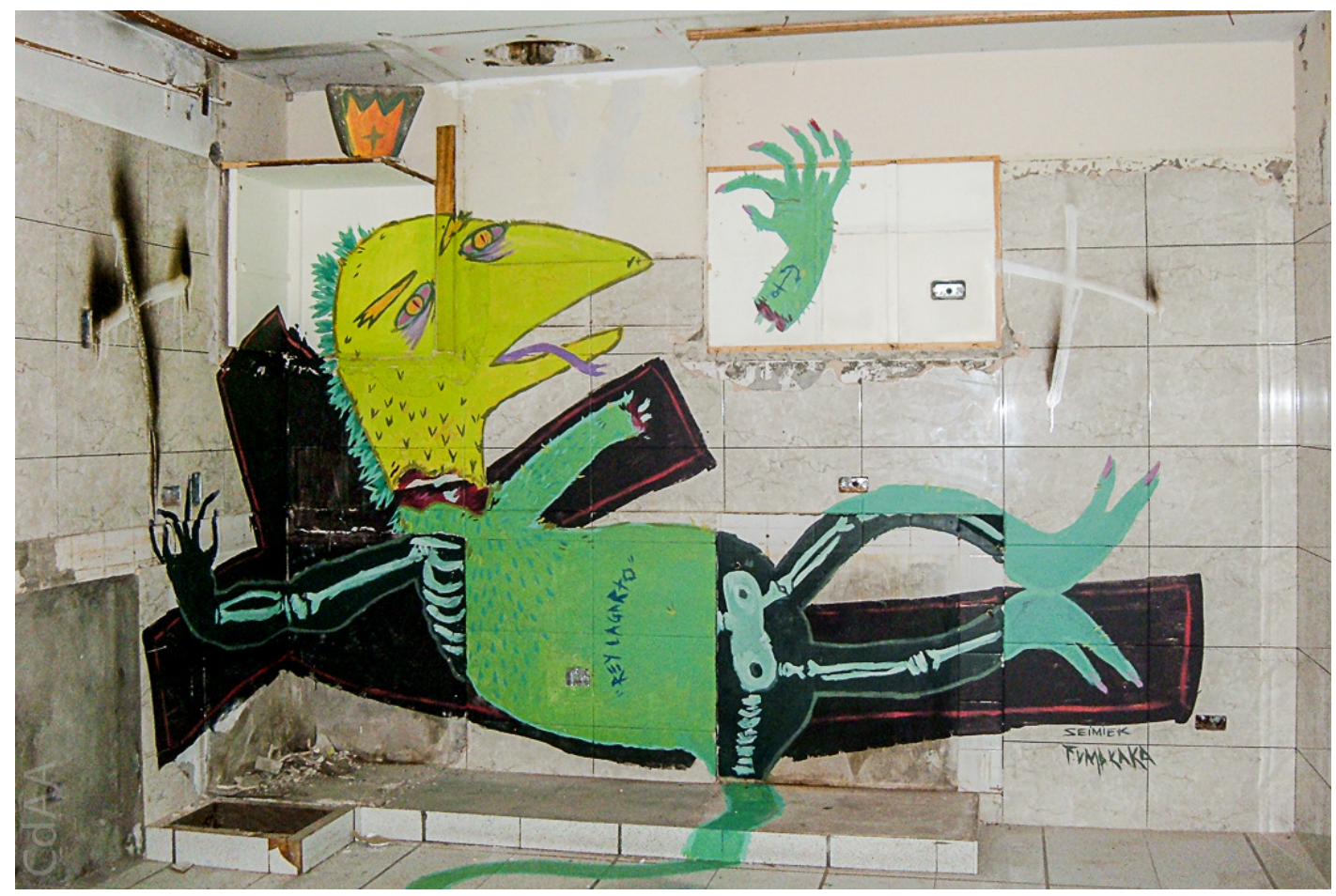

Foto 2. Fotografía por Orietta Marquina Vega.

\section{REFERENCIAS}

Appadurai, Arjun. 2015. El futuro como hecho cultural, Ensayos sobre la condición global. Buenos Aires: Fondo de Cultura Económica.

Aubán, Mónica (2017). "La dignidad de los márgenes. Aproximaciones afectivas a la ciudad informal”. Revista INVI, 32(91), 67-89 Recuperado de http://revistainvi.uchile.cl/index. $\mathrm{php/INVI/article/view/1223/1334}$

Bakko, Matthew y Sibille Merz. 2015. "Towards an Affective Turn in Social Science Research? Theorising Affect, Rethinking Methods and (Re) Envisioning the Social”. Graduate Journal of Social Science, 11(1), 7-14. Recuperado de http://eds.b.ebscohost.com.ezproxybib.pucp.edu.pe:2048/eds/pdfviewer/pdfviewer?vid=5\&sid=e6d1d321-87ae-4ae6-9cc0-979b27489809\%40pdc-v-sessmgr01

Ballón, Eduardo; Alvaro Campana y Marisa Glave. 2015. "Ordenamiento territorial: entre el entrampamiento y normativo y la reterritorialización del capital”. En Perú Hoy, Hacia otro desarrollo, edited by Ivan Medoza, 153-176. Lima: Desco. Recuperado de http://www. desco.org.pe/hacia-otro-desarrollo-serie-peru-hoy-n\%C2\%BA-28-diciembre-2015

Bärb, J. y Borsdorf, A. (2005). "La ciudad latinoamericana, la construcción de un modelo, vigencia y perspectivas”. ur[b]es, Revista de ciudad, urbanismo y paisaje. Año II, No 2, Lima: gecup-UNI Recuperado de https://www.guzlop-editoras.com/web_des/arquit01/pld0472.pdf 
Boler, Megan y Michalinos Zembylas. 2016. Entrevista con Megan Boler: From 'Feminist Politics of Emotions' to the 'Affective Turn." En Methodological Advances in Research on Emotion and Education, editado por Michalinos Zembylas y Paul Schutz, 17-30. Basel Springer International Publishing. Recuperado de https://www.springer.com/ cda/content/document/cda_downloaddocument/9783319290478-c2.pdf?SGWID=0-0-45-1552081-p178380907

Colectivo Extramuros. Julio 2008. “Quiénes somos?” Colectivo Extramuros [Blog]. Recuperado de https://colectivoextramuros.blogspot.com/

Cuba, Elmer. 2013. “¿Burbuja o boom inmobiliario?” DiarioPerú21 [on Line], Marzo 18. Recuperado de https://peru21.pe/opinion/burbuja-boom-inmobiliario-97813

CVR (2003). "Conclusiones generales". En: Informe Final de la Comisión de la Verdad y Reconciliación (CVR). Lima: CVR. 315-345 Recuperado de http://cverdad.org.pe/ifinal/ pdf/TOMO\%20VIII/CONCLUSIONES\%20GENERALES.pdf

De Certeau, Michel. 1996. La invención de lo cotidiano. Tomo I Artes de hacer. Ciudad de México: Universidad Iberoamericana A.C.

Good Bye Casa. Setiembre 2008. Good Bye Casa, proyecto artistico multidisciplinario [Blog]. Recuperado de http://goodbyecasa.blogspot.com/

Ingold, Tim. 2013. Making. Anthropology, archaeology, art and architecture. London: Routledge.

Kraftl, Peter y Peter Adey. 2008. "Architecture/Affect/Inhabitation: Geographies of Being-In Buildings". Annals of the Association of American Geographers, 98(1): 213-231 Recuperado de https://doi.org/10.1080/00045600701734687

Ludeña, Wiley. 2010. "Lima. Reestructuración económica y transformaciones urbanas. Período 1990 - 2005." Cuadernos de arquitectura y ciudad, N¹3, edición digital 009, noviembre 2010. Lima: Departamento de arquitectura, Pontificia Universidad Católica del Perú. Recuperado de http://departamento.pucp.edu.pe/arquitectura/files/2012/03/cuadernos-13.pdf

Marquina, Orietta. 2008. "No me toques, que te toco... No me hieras, que te hiero...". Orietta Marquina BlogSpot [On Line], Setiembre 4, 2008 Recuperado de http://oriettamarquina. blogspot.com/search/label/Intervenciones\%20de\%20Espacios

Macher, Sofia. 2012. "Balance Final Report Truth and Reconciliation Commission, 9 years of submission”. Revista Tarea, No 81, Setiembre 2012, 1-6 Recuperado de http://tarea.org. pe/images/Tarea81_02_Sofia_Macher_ingles.pdf

Maíz, Claudio. 2001. "Nuevas Cartografías Simbólicas. Espacio, identidad y crisis en la ensayística de Manuel Ugarte”. En Ciberletras [electronic resource]: revista de crítica literaria $y$ de cultura. Lehman College - CUNY, vol. 05. Recuperado de http://www.lehman.cuny. edu/ciberletras/v05/maiz.html

Navaro-Yashin, Yael. 2009. "Affective spaces, melancholic objects: ruination and the production of anthropological knowledge". En Journal of the Royal Anthropological Institute, 15(1), 125-135. Recuperado de http://asiapacific.anu.edu.au/sites/default/files/cap_events/attachments/2014/Nov/Reading\%203.pdf

Stewart, Kathleen. 2017. "In the world that affect proposed". Cultural Anthropology, 32, $\mathrm{N}^{\circ} 2$, 192-198. Recuperado de https://doi.org/10.14506/ca32.2.03

2010. "Afterword, Worlding Refrains". En: The affect theory reader, edited by Melissa Gregg y Greg Seigworth, 339 - 353. Durham: Duke University Press. Recuperado de https://mastersofsexshortcourse.files.wordpress.com/2016/04/melissa-gregg- gregory-j-seigworth-the-affect-theory-reader-duke-university-press-2010.pdf 
Stoler, Ann L. 2008. “Imperial Debris: Reflections on Ruins and Ruination.” Cultural Anthropology, Vol. 23, No. 2, Imperial Debris, Mayo 2008, 191-219. Recuperado de https://web-jstor-org.ezproxybib.pucp.edu.pe/stable/pdf/20484502.pdf?refreqid=search\%3A4627c863aadfec5eda1305e4c03c1541

Wiese, Claudia, Jaime Miyahiro y Rebeca Marcés. 2016. "Desigualdad urbana en Lima Metropolitana”. En Perú Hoy, Desigualdad y desarrollo, compiled by Werner Jungbluth, 33-369. Lima: Desco. Recuperado de http://urbano.org.pe/descargas/investigaciones/ PERU-HOY/PH_dic16_vf.pdf

\section{"Good Bye Casa", A Creative Cure in Lima, Peru for the Dismantling OF THE CITY}

After implementing a neoliberal economic program and imprisoning Abimael Guzmán, head of the terrorist group Sendero Luminoso, the landscape of Lima had changed. Many of the most economically solvent people had fled the country because of the internal war that ravaged Peru. Their houses, now, were to give way to new inhabitants of Lima. Economic growth brought new foreign capital interested in investing, but also new ways of living and inhabiting the city. A number of female artists organized artistic interventions in that were about to be demolished, as resistance to the new social relationships that the new buildings proposed to the city and its new inhabitants. There was no room for boys playing soccer in the streets or girls and boys firting in the corners. Young artists decided to witness from the ruins, at least for a few days, the world they were forced to say goodbye to.

Keywords: affects, urban transformations, urban abandonment, art interventions, urban ruins

Data recibido: 2019-08-24

Data aceptado: 2020-04-07 